\title{
El olvido heideggeriano del Ser (como génesis intensiva). A propósito de la disolución fenomenológico-aleteiológica de la physis
}

\section{The Heideggerian Forgetting of the Being (as Intensive Genesis). About the Phenomenological- Aleteiological Dissolution of Physis}

\author{
Luis Sáez Rueda ${ }^{1}$ \\ Universidad de Granada (España) \\ ORCID: https://orcid.org/0000-0003-1490-3334
}

Recibido: 01-11-2020

Aceptado: 15-12-2020

\section{Resumen}

El ensayo parte de la concepción heideggeriana del ser como una diferencia de carácter fenomenológico-aleteiológico, es decir, como acontecimiento de "sentido" y de la verdad del ser. El autor defiende que es posible pensar una diferencia óntico-ontológica de carácter genético-intensivo no reductible a la anterior e inherente a la noción de physis. Heidegger, según la tesis central, diluye la segunda en la primera, ofreciendo como única alternativa una comprensión devaluada de la génesis como devenir óntico, alternativa que liga al olvido del ser. Olvida, así, y a su pesar, al ser, comprendido al modo genético y diferencial. Se analiza este olvido en varios contextos: el de la confrontación de Heidegger con Nietzsche, el de su interpretación del devenir y el de su asimilación del idealismo alemán. Al ir caracterizando al ser como génesis son injertados por el autor puntos de vista de G. Simondon, G. Deleuze, Schelling y Hölderlin.

Palabras-clave: diferencia óntico-ontológica, génesis, physis, Heidegger, Nietzsche, Simondon, Deleuze, idealismo alemán.

\footnotetext{
${ }^{1}$ (1saez@ugr.es). Profesor en el Departamento de Filosofía II de la Universidad de Granada. En la primera fase de su investigación analizó el trazado de las corrientes contemporáneas de pensamiento, ante todo en Movimientos filosóficos actuales (2001) y El conflicto entre continentales y analíticos (2002). Se ha ocupado, en esa línea, de problemas como el del nihilismo y el del malestar colectivo de nuestra época. En su fase más reciente de investigación desarrolla una comprensión tensional de la realidad junto a su aplicación a la crítica de la crisis civilizacional, en libros como Ser errático. Una ontología crítica de la realidad (2009), El ocaso de Occidente (2015) y Tierra y Destino (2021). Sus publicaciones son accesibles en la siguiente página web: http://www.ugr.es/ lsaez/cv/Welcome.html
} 


\begin{abstract}
The essay starts from the Heideggerian conception of being as a difference with a phenomenological-aleteiological character, that is, as an event of sense and of the truth of being. The author defends that it is possible to think an ontic-ontological difference with a genetic-intensive character that cannot be reduced to the previous one and is inherent in the notion of physis. Heidegger, according to the central thesis, dilutes the second in the first, offering as the only alternative a devalued understanding of genesis as ontic becoming, an alternative that links to the forgetting of being. Therefore, and despite himself, he forgets being, understood in a genetic and differential way. This forgetting is analyzed in various contexts: that of Heidegger's confrontation with Nietzsche, that of his interpretation of becoming and that of his assimilation of german idealism. By characterizing being as genesis, the author inserts various points of view of G. Simondon, G. Deleuze, Schelling and Hölderlin.
\end{abstract}

Keywords: ontic-ontological difference, genesis, physis, Heidegger, Nietzsche, Simondon, Deleuze, german idealism.

\title{
Consideraciones iniciales
}

En su crítica a la Metafísica Heidegger denuncia, como es sabido, el olvido del ser, consistente en su reducción al ente. En la culminación presente de la voluntad de dominio que acompaña a este olvido, la naturaleza, como una esfera más de lo ente, es sojuzgada:

El ser humano está a punto de abalanzarse sobre la totalidad de la tierra y su atmósfera, de arrancar y obtener para sí el escondido reino de la naturaleza bajo la forma de fuerzas y de someter el curso histórico a la planificación y el orden de un gobierno terrestre (1995: 247)

Cabría preguntar de qué modo podría ser sustraída la naturaleza, en la superación de la metafísica, a su reducción óntica. ¿Tal vez reinstaurando una relación con ella que recobrase -al modo presocrático- su carácter ontológico en cuanto physis? ¿O, más bien, aprehendiéndola como una de las expresiones del ser? ¿Decimos lo mismo en ambos casos?

Estas cuestiones, que afectarían a la hoy tan necesaria reflexión acerca del peligro ecológico que atravesamos, no son las que serán tomadas aquí como objeto de investigación explícita. Han sido introducidas para sugerir la relevancia que posee la cuestión que sí desarrollamos. Quisiéramos mostrar, exclusivamente, que la ontología del sentido heidegeriana desestima 
la comprensión del ser como génesis intensiva que podemos ligar a la idea de physis. La desestima al integrar, por un lado, el ámbito ontológico de la génesis en el de la venida a presencia del sentido y al reducir, por otro, la pretensión de preservar su especificidad a una consideración meramente óntica de la naturaleza. El olvido del ser tematizado por Heidegger no es puesto en cuestión aquí de modo radical y completo. Es problematizado en cuanto a su confinamiento en una ontología fenomenológico-aleteiológica que tiene como condición el olvido del ser como génesis intensiva.

La argumentación sigue diversos escenarios con cierto tempo dialéctico. Comenzamos especificando la asimilación heideggeriana del devenir generativo-destructivo de la physis en el acontecer desocultante-ocultante del ser, así como la reducción de su afirmación -de ascendencia nietzscheana- a la idea de un devenir óntico presidido por el eterno retorno de lo Mismo (§ 1). Caracterizamos a continuación la génesis, en su generalidad, como un devenir que, por el contrario, implica una diferencia óntico-ontológica (intensoextensiva), para mostrar cómo Heidegger asimila, en la raíz de su filosofía, tal devenir a la esenciación del ser en su sentido fenomenológico-aleteiológico, reduciendo, renovadamente, cualquier alternativa a la metafísica subjetivista latina, que lo convertiría en un hacer exitoso ( $(2)$. Finalmente, presentamos dos escenarios que pueden apoyar el carácter irreductible de una ontología del ser como génesis intensiva ( $\$ 3)$. En primer lugar, la comprensión simondoniana y deleuzeana de la diferencia, desde la cual, por lo demás, se puede salvar a Nietzsche de la crítica heideggeriana y mostrar que es el devenir concebido por Heidegger el que está propiamente imantado por el eterno retorno de lo Mismo (§ 3.1). En segundo lugar, el vínculo entre lo aórgico y lo orgánico en el idealismo alemán, cuyos rasgos generales apoyarían más a la línea anterior que a la asimilación heideggeriana de este movimiento (§3.2).

\section{Génesis physica vs. des-ocultamiento. Heidegger ante Anaximandro y Nietzsche}

La conocida e inquietante sentencia de Anaximandro en la que el filósofo presocrático remite la génesis de las cosas al fondo indeterminado del mundo natural, lo ápeiron, y vincula ese proceso a una lucha inevitable entre surgimiento y destrucción en el tiempo ha dado lugar a las interpretaciones polares de Nietzsche y de Heidegger, no exentas de dramatismo. Dice la sentencia, tal y como la transmite Simplicio:

[El arjé] no es agua ni ningún otro de los denominados elementos, sino alguna otra naturaleza ápeiron, a partir de la cual se generan todos los cielos y los mundos que hay en ellos. Ahora bien, a partir de donde hay generación para las cosas, hacia allí también se produce la destrucción, según la necesidad; en 
efecto, se pagan mutuamente culpa y retribución por su injusticia, de acuerdo con la disposición del tiempo (D-K: 12 A 9).

Nietzsche confiere a la sentencia un sentido ontológico y otro moral. Se referiría, en primer lugar, al principio de individuación inherente a la physis, según el cual lo ilimitado y eterno (ápeiron) se constituye en matriz del continuo originarse, adquiriendo límite en lo individual concreto y reasumiendo a todo lo existente tras su aniquilación (2003: 48). De acuerdo con su sentido moral, implicaría un pesimismo decadente; asumiría que lo que deviene se separa de lo eterno y sufre por ello un castigo, ligado a la injusticia del nacer y declinar (id.: 49). Hay que apresurarse a señalar que Nietzsche redime a Anaximandro a lo largo de su obra, pues lo hace partícipe, como filósofo presocrático, de ese pesimismo de la fortaleza y trágico que asume lo terrible del devenir, pues se trata ahí de una predilección por lo problemático surgida de una "salud desbordante" (2002: 26; v. Ávila Vázquez 2011). Ahora bien, en la sentencia radica también -nos advierte el filósofo- el comienzo de una valoración autodisolvente de la vida que, erigiéndose ya en predominante desde el mundo socrático, empapa la historia europea, a saber, la valoración según la cual el devenir y la continua transfiguración de la multiplicidad, fuentes de ruina y devastación, convierten a la vida en algo insoportable y sin sentido. Asumido desde la debilidad, este pesimismo se desarrolla en nihilismo: voluntad de nada y negación de la vida (1986: 267, 9 [107]).

Ante semejante ocaso habría que retomar, nos sugerirá Nietzsche, el lazo con aquella visión griega de la naturaleza que destella aún en la sentencia y que la comprende como physis. Y es que tal comprensión está en concordancia con la superación del nihilismo, que incluye la necesidad de "imprimir al devenir el carácter del ser" (Nietzsche 1986: 221, 7 [54]). El devenir y, por tanto, el mundo alterante de la pluralidad en el que generación y destrucción entran en litigio, debe, según ello, ser contemplado desde el mundo de fuerzas que lo habitan inmanentemente. Y en la physis contempla Nietzsche esa diferencia y vínculo simultáneos entre la pluralidad tangible de lo que deviene y la profundidad gestante del devenir mismo. Tal conformación destella en la unidad dionisíaco-apolínea como un dinamismo genético por el cual un fondo informe, convulsamente oscuro y plagado de fuerzas (ápeiron dionisíaco) produce una multiforme y prolífica vida concreta, al arremansarse en los límites apolíneos bajo multitud de con-formaciones. Inserto en esa physis generadora, coloca el ser humano lo terrorífico del devenir -generador y aniquilador a un tiempo- al servicio de la vida creciente, orientando tal fondo a que in-forme los productos de la creación y de la bella medida. "Esta armonía, más aun, unidad del ser humano con la naturaleza, contemplada - dice Nietzsche- con tanta nostalgia por los hombres modernos" (...) alcanza el límite mesurado si ha "obtenido la victoria, por medio de enérgicas ficciones (...), sobre la horrorosa profundidad" (2002: 56).

Araucaria. Revista Iberoamericana de Filosofia, Politica, Humanidades y Relaciones Internacionales, año $23, \mathrm{n}^{\circ} 48$. Tercer cuatrimestre de 2021. Pp. 79-100. ISSN 1575-6823 e-ISSN 2340-2199 https://dx.doi.org/10.12795/araucaria.2021.i48.04 
No menos significativa resulta a los ojos de M. Heidegger la sentencia, "la más antigua del pensamiento occidental" y, sin embargo, próxima a nosotros, en la medida en que, advirtiéndonos sobre un ocaso, nos "habla de lo que está por venir" (1995: 242-243). Ahora bien, Anaximandro no se referiría -señala el autor alemán- a la naturaleza en cuanto un dinamismo físico-genético, sino al ser como diferencia óntico-ontológica. Destacar el nacer y expiar de las cosas como el devenir de la physis constituiría, más aún, un "prejuicio" de la "filosofía de la naturaleza" (id.: 247). Establece la sentencia, sí, una

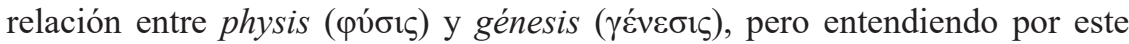
último fenómeno un "salir fuera" [Entgehen] que surge de lo oculto y "lo deja emerger [hervorbringen] en lo no oculto" (id.: 254; GA...). El conflicto, en consecuencia, entre génesis y destrucción que acompaña al devenir habría que leerlo en clave aleteiológica, como la relación entre des-cubrimiento (alétheia) de la verdad del ser y su simultáneo encubrimiento u ocultación, relación que a menudo conceptualiza Heidegger como una auténtica lucha inherente al ser como diferencia (2003: $\S 144)$. La primera parte de la sentencia diría, entonces: "Pero a partir de donde el surgir es para las cosas, también surge allí el sustraerse" (1995: 245). Ambos, descubrimiento y encubrimiento, mantienen una contienda diferencial, de modo que si se le atribuye una justicia (diké) es -añade Heidegger- en el sentido de un acuerdo ensamblante (Fug) que siempre puede ser desatendido por el ser humano y conducido a la injusticia (a-dikia) del des-acuerdo (Un-fug), es decir, al olvido del ser en favor de la prevalencia de la mera presencia de lo descubierto. La sentencia nos advierte, por tanto, sobre este peligro y sobre la necesidad de repararlo. Los seres humanos, como los que moran en el ser -y aquí se incrusta la traducción heideggeriana de la segunda parte de la sentencia- "dejan que tenga lugar acuerdo (Fug) y por lo tanto también atención mutua (en la reparación) del des-acuerdo (Un-Fugs)" (id:: 269; GA, 5: 361). Y es precisamente la desatención lo que ha vencido históricamente, es decir, el olvido del ser.

A este olvido habría contribuido de forma determinante la comprensión de la physis, no como acontecimiento del ser, sino como naturaleza en devenir. "Las teorías de la naturaleza (...) confunden todo hasta volverlo irreconocible, porque ellas mismas se alimentan de esa confusión que planea sobre la diferencia entre lo ente y el ser" (id.: 277). Como consecuencia, la misma naturaleza está, como hemos señalado al inicio, amenazada esencialmente por la voluntad de dominio del ser humano. El olvido del ser ha implicado, para conducir a este resultado, que el devenir sea reducido a un proceso meramente óntico y, consecuentemente, susceptible de ser puesto a disposición del sujeto, del valor que para él tenga. Bajo la denuncia de la devaluación del devenir como gesto central del nihilismo reactivo -en el pensamiento de Nietzschehabría, por ello, una más profunda nihilización del ser: lo reduce a valor y, así, 
a lo pro-puesto y dispuesto por la voluntad de poder (2000a II: 277), la cual no es, en el fondo, más que voluntad de auto-aseguramiento ( $c f$. id. II: 108-114).

Desde este olvido es preciso, entonces, comprender la vocación nietzscheana de "imprimir al devenir el carácter del ser". La afirmación de un devenir genético -de generación y destrucción- al margen del devenir en su sentido fenomenológico-aleteiológico -como des-ocultamiento- sólo puede significar, para Heidegger, que la idea de la naturaleza como physis es engullida en la auto-afirmación de la voluntad, cuya incondicionalidad es lo que, en el fondo, expresaría el pensamiento nietzscheano del eterno retorno de lo mismo (1995a: 247). De esta forma, la "temprana sentencia del pensamiento primigenio" -la de Anaximandro- se cruza, curiosamente, con la "tardía sentencia del tardío pensamiento" (id.). Aquélla advertía sobre la posibilidad del olvido del ser, ésta lo consuma.

\section{La tenaza sobre el devenir genético-intensivo: o bien disolución fenomenológico-aleteiológica o bien reducción óntica}

Mediante la crítica anterior Heidegger sólo ofrece dos opciones a la idea de un devenir genético: o es disuelto en el fenomenológico-aleteiológico o debe ser entendido como pretensión de una óptica que lo reduce a un devenir óntico puesto al servicio de la voluntad de dominio. Dejamos en suspenso, por el momento, lo que concierne al pensamiento de Nietzsche para intentar mostrar que esta figura atraviesa al pensamiento heideggeriano de un modo constitutivo, esencial. Antes de ello, empero, comenzaremos a caracterizar, con ayuda de G. Deleuze, al ser en cuanto génesis intensiva.

En su acepción más elemental, podemos decir que la génesis intensiva es la relación de engendramiento de una dimensión extensiva desde otra intensiva. La intensio es la cualidad de la fuerza, por lo que compete a una ontología de la potencia. G. Deleuze describe algunos rasgos interesantes de este proceso de génesis. Hay que advertir con antelación que la esfera extensiva no coincide sin más con un plano geometrizable. Del latín extenš̌o, indica el ámbito de las conformaciones - naturales, humanas o culturales- que se extienden en determinados límites, por contraposición al carácter ilimitado e informe (ápeiron) de lo intensivo. Dicho esto, hay que señalar, en primer lugar, que si la conformación extensiva es perceptible o representable, la intensio generadora subtiende ambos dominios, siendo, ella misma, imperceptible e irrepresentable. Es afectante. Este carácter resulta fundamental en nuestro contexto de reflexiones, pues ofrece su diferencia central respecto al "sentido" (del acontecer). Éste se presta a la aprehensión o interpretación comprensiva; lo intensivo se caracteriza por la capacidad de afectar y de ser afectado (Deleuze 1986a: 90-91). En segundo lugar, cabe señalar que 
intensio y conformación extensiva constituyen una única realidad internamente diferencial: la intensio es una profundidad ontológica informal que es o existe realizada en los límites extensivos, los cuales le otorgan corporalidad sensible (id.: 345-346; cfr. 344-361).

La physis se hace comprensible desde una ontología de la génesis intensiva así descrita. Según su sentido más originario, es el llegar a ser lo real en su multiplicidad y devenir (Calvo Martínez 2000: 26 y 33-36). Como dimensión intensivo-extensiva, es ápeiron limitado. El razonamiento que conduce a este resultado se destiló en la filosofía presocrática (id.: 31-32). Se autogenera la physis partiendo de un primer principio o arjé. En él se funda el comienzo de la guénesis ( $\gamma \varepsilon ́ v \varepsilon \sigma ı \zeta)$, un término que significa "nacimiento", "creación", "origen", y que se forma a partir de las palabras phio phiomai (

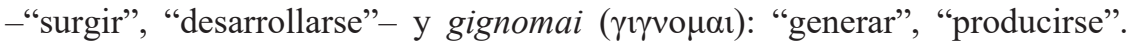
Ahora bien, hablar de un arjé conduce a preguntar por otro anterior en un regreso al infinito. El arjé, pues, debe ser inengendrado, eterno y permanentemente activo. Y ésta fue la clave para pensar el fondo último de la physis en la versión de Anaximandro. El arjé ha de poder originar, encontrando limitación (péras), todo lo existente. En cuanto ápeiron, no está "presente" en la physis como lo están las realidades concretas -no es óntico-; atraviesa a cada ser como su dimensión invisiblemente ordenadora. Por su propio sentido, pues, la génesis que tiene lugar en la physis remite a una diferencia - a nuestro juicio- ónticoontológica, aunque bien distinta de la pensada por Heidegger. El ocultamiento, en este contexto, adquiere un sentido distinto: in-sistencia irrepresentable e incorpórea en todas las corporeizaciones representables.

La asimilación heideggeriana de la génesis intensiva al acontecer del ser depende de la ontología fenomenológica del sentido que es expresa desde Sein und Zeit. La ontología, decía allí, sólo es posible como fenomenología, el saber de los fenómenos. El fenómeno, en su acepción fenomenológica, consiste en el aparecer mostrativo de "sentido", "entiende por 'lo que se muestra' el ser de los entes, su sentido, sus modificaciones y derivados” (1951: 46). La única alternativa a este punto de partida residiría en la comprensión del fenómeno en su "sentido vulgar", que se refiere al aparecer óntico en el puro aspecto, uno de cuyos modelos explicativos más señalados es el kantiano (id.: 41). Una posible ontología de la génesis no era aquí, por tanto, contemplada, sino, a nuestro juicio, sustituida por la reducción que representa el naturalismo científiconewtoniano, asumido en parte por Kant. Quedaba, así, cerrada la posibilidad de pensar la pertenencia del ser humano a la naturaleza como physis en su carácter genético.

A partir de la Kehre queda más claro que cualquier espacio de pertenencia al que remite el ser humano ha de ser pensado como ámbito manifestativo de sentido por el cual el ser acontece. El mostrarse de los fenómenos es tematizado 
como diferencia óntico-ontológica que requiere al ser humano y permite una recíproca respectividad. En cuanto Ereignis, el acontecimiento tiene lugar propiamente en el "claro" [Lichtung], que "permite al ser y al pensar advenir a su presencia (...) uno a otro y uno para otro (...); es el asilo en cuyo seno encuentra su sitio el acorde de ambos" (Heidegger 1968: 146).

Es cierto que el ser, así concebido, es retrotraído al acontecimiento inicial en cuanto physis, "fuerza imperante" (Walten) y "erguirse que brota" -aufgehende Sichaufrichten-(2001b: 63; GA 40: 65). Parecería que este gesto está reconociendo en la naturaleza la radicalidad esencial de un ser genético-intensivo e invocando la pertenencia recíproca entre tal naturaleza y el ser humano. En tal caso se entendería muy bien que el olvido del ser (como génesis) provocase el "abalanzarse sobre la totalidad de la tierra y su atmósfera", según las palabras proféticas señaladas más arriba. Ahora bien, ocurre, por el contrario, que tal dimensión de potencia es equiparada por Heidegger al movimiento -fenomenológico-aleteiológico- por el cual dicha "fuerza imperante", sin embargo, surge de lo oculto, teniendo lugar en ella la alétheia (el desocultamiento). La physis se equipara, así, con el "devenir mundo" (Weltwerden), es decir, con el des-cubrimiento de un mundo de sentido, con el aparecer como la "epifanía de un mundo" (Epi-phanie einer Welt) (id.: 63-64; GA 40: 66-67). Rebasar el olvido del ser, cuyos efectos aniquiladores advertía, según Heidegger, la sentencia de Anaximandro, implica que el ser humano se inserte en un devenir peculiar, en un devenir mundo que acaece por mor del ser. No debe ser confundido éste, pues, con una relación nueva del ser humano con la physis, entendida como ser genético-intensivo y, por tanto, con el agenciárselas en el seno de un devenir propio de éste. Pero, ¿qué significa, en este contexto, “devenir"? La interpretación heideggeriana del modo en que Aristóteles entiende la physis nos aproxima a una respuesta a cuyo través reduce el devenir genético a un discurrir meramente óntico, convirtiéndolo en origen de efectos devastadores.

Aristóteles, como se sabe, considera, en la Física, al movimiento como el modo fundamental de la naturaleza. Intentando recuperar el sentido originario de esta noción en lo impensado del pensar aristotélico, Heidegger pretende alejar su interpretación como cambio de lugar, sustituyéndola por una comprensión fenomenológica que lo descubre como un "llegar a la presencia" (2000b: 207). La primera acepción rige en el más vulgar concepto del devenir, el cual vincularía el movimiento del surgir en la physis al proceso -horizontal, si se nos permite una metáfora espacial-del "transcurrir" y desaparecer (2003: $\S 99,163)$. La segunda, por el contrario, pone en juego al movimiento-vertical, continuando la metáfora- del acontecimiento de ser. Tal interpretación parte de la consideración aristotélica del movimiento como el acto de lo potencial en tanto que tal (Física, 201a 27-29). Heidegger entiende el movimiento (kínesis) 
como enérgeia atelés, un "estar en obra" en el que se mantiene la potencia (dinamis), entendida como "venida a la presencia" (2000b: 237). Y puesto que esta última es alétheia, se puede decir que, así, el movimiento es interpretado al modo fenomenológico-aleteiológico (Segura Peraita 2018). Pues bien, que la génesis ( $\gamma \varepsilon \dot{v} \varepsilon \sigma ı \varsigma)$ constituya un movimiento en la physis sólo puede significar el propio "estar en camino" del ser en la articulación diferencial entre la salida a la presencia y el simultáneo retorno al ocultamiento (Heidegger 2000b: 240242), articulación a la que remitirían, en el fondo, los procesos de generación y corrupción, caras opuestas de la génesis ( $c f . i d$. 247).

Más allá de la exégesis del movimiento en Aristóteles, cabe decir que engendramiento y destrucción, en un sentido general, son absorbidos en esta acepción fenomenológico-aleteiológica porque el genuino devenir, según nuestro autor, no tiene lugar en la physis como un conflicto, de corte genético, entre la gestación del ser determinado a partir de lo indeterminado, por un lado, y su necesaria aniquilación y reintegración en este último, por otro. Y es que lo ilimitado de la physis (ápeiron) debe ser comprendido, según Heidegger, como la propia apertura (de sentido) desfundada del ser: "lo abierto es el espacio de juego de lo que aún es indeterminado". El genuino de-venir va de lo ápeiron, o apertura indeterminada, a

"lo desoculto (...), [que] puede significar en lo sucesivo también 'meta' [Ziel]. (...) Pensada de manera moderna, una 'meta' es sólo el suministro de una 'estación intermedia' dentro de lo ilimitado [Grenzenlosen] de los resultados y operaciones siempre crecientes. El límite (péras), pensado por los griegos, no es, empero, aquello en lo cual algo cesa [wobei etwas aufhört], sino aquello en lo cual algo emerge [worein es entsteht], en tanto se origina como ser "formado" [“gestaltet"] de este o aquel modo" (2005a: 107; GA 54: 121).

Este de-venir inherente al acontecimiento del ser no posee, como señala con agudeza Rojas Jiménez (2012: 390) un fin (Ende), sino una finalidad (Ziel), a saber, la de que el ser tiene que determinarse para ser. Coincide con la determinación misma del ser en un mundo concreto de sentido y por mor de la diferencia óntico-ontológica: no es un "suceder" o "pasar" (Geschehen), sino un “envío” (Geschickt) o "asignación” (Zuweisung) del emerger (GA 54: 81). Su temporalidad, expresado de otro modo, no es la de la fugacidad-Flüchtigkeit(2003: 164; GA 65: 195), sino la de su propia ex-posición o esenciación: es "éxtasis (Entrückung)", "inauguración” (Eröffnung)" y "se esencia (west) en la esencia de la verdad" (id.: 162; GA 65: 191-192).

El olvido del ser, cabe deducir de estas consideraciones, habría malinterpretado el devenir genético-intensivo de la physis como un mero proceso óntico, consistente, además, en dar alcance a un fin en cuanto acabamiento. De ahí que pueda ser entendido, finalmente, como un hacer productivo que 
consuma una obra exitosa, capitaneado por el impulso subjetivo al dominio. El actus de esta génesis devaluada, que el mundo latino pone en vigor, estaría en conexión, en definitiva, con una realidad minimizada a la función de efecto respecto a una causa efficiens (cfr. Heidegger 2001a: 33-50 y 35-37).

\section{Irreductibilidad del de-venir genético-intensivo al fenomenológico- aleteiológico}

Quisiéramos mostrar que una ontología del ser como génesis intensiva no está condenada a entender el devenir al modo reductivo descrito. Le es inherente su propia e irreductible diferencia óntico-ontológica en la dimensión del emerger engendrador, circunstancia que pertenece al peculiar olvido heideggeriano del ser que venimos comentando. Esta tesis pide desarrollos más minuciosos de los que aquí pueden ser aportados. Nos parece suficiente, sin embargo, reconstruir dos campos problemáticos que la ponen en juego. El primero hace valer una línea de pensamiento en la que se cruzan Nietzsche, Simondon y Deleuze. El segundo concierne al nexo entre lo aórgico y lo orgánico implícito en el idealismo alemán.

\subsection{Generación y destrucción genético-intensiva en cuanto tensión diferencial y destrucción identitaria. De Nietzsche a Simondon y Deleuze, frente a Heidegger}

Es posible discernir el devenir genético-intensivo -frente a lo que Heidegger admitiría- como un acontecimiento ontológico irreductible al fenomenológico-aleteiológico y distinguible del discurrir óntico orientado a una meta. Intentaremos delinear su textura como la de un emerger en virtud del cual la generación consiste en la auto-diferenciación de un ser intensivo-relacional a través de su determinación individuadora, de tal modo que esta última incorpora una diferencia tensional interna; la de-generación (aniquilación o destrucción) sería pensable como reducción de tal diferencia tensional a una identidad consigo mismo. La línea de pensamiento que va de Nietzsche a Deleuze y pasa por Simondon puede ser interpretada de este modo. Tras esbozarla extraeremos consecuencias críticas con la perspectiva heideggeriana.

La invocación de una inmersión salutífera en la naturaleza dionisíacoapolínea que realizaba Nietzsche como afirmación del devenir depende de una ontología de la potencia, de la fuerza. Hay razones para sostener que, si el carácter del devenir pudo ser pensado como voluntad de poder, no es porque ésta emane de una supuesta esfera reforzadora de la subjetividad, sino porque, antecediendo genéticamente a ésta -como intenta mostrar Deleuze-, acontece 
en cuanto articulación relacional de fuerzas. En la medida en que no coincide con las fuerzas mismas, su textura no es óntica. Éstas, en tanto dinamismos intensivos caracterizados -como hemos señalado más arriba- por la capacidad de afectar y ser afectados, sólo son en la medida en que se encuentran y se entrelazan. El ser se pone en obra, desde este punto de vista, como diferenciante de las fuerzas y, así, como el sin-fondo de un afuera informal -un ápeiron, pues-, cuya determinación o actualización da cuenta de las realidades concretas (cfr. Deleuze 2015: cap. I). El ser impensado y supuesto en el pensamiento nietzscheano no coincide, desde esta perspectiva, con el valor. Ha de ser pensado como el de-venir o emergencia de este afuera genético-intensivo y, en este sentido, como diferencia entre él, en cuanto profundidad in-sistente, y su conformación extensiva (Deleuze 1986a: 73-77; 2002: 203-206).

El devenir de esta génesis que pensamos ayudándonos de nociones deleuzeanas es, a nuestro juicio, el acontecer de una diferencia ónticoontológica, con tal de que se entienda como emergencia engendradora de carácter intensivo. Posee su propio ser acontecimental y su específico desfondamiento o sustracción. En la medida en que la generación tiene lugar como relación diferencial, está ligada, en efecto, a una peculiar "nada" o abismo (Ab-grund): el propio intermezzo disyuntivo. Foucault lo ha aclarado lúcidamente al referirse a eso que Nietzsche entiende por "génesis de un fenómeno" como

"la emergencia [Entstehung] [que] se produce siempre en un determinado estado de fuerzas. El análisis de la Entstehung debe mostrar el juego [entre éstas], la manera como luchan unas contra otras (...). El lugar de surgimiento [es] un no lugar, una pura distancia (...); ésta se produce siempre en el intersticio" (Foucault 1991: 15-16).

No es integrable la noción de este devenir en la idea de la esenciación del ser, entendido fenomenológico-aleteiológicamente. Pues no posee un carácter mostrativo (de sentido), sino operante (afectante). Acontece -como veremos en breve- en la medida en que el fondo informal e intensivo se diferencia inmanentemente al determinarse, y este dinamismo pone en vigor relaciones intensivas cuyo ser consiste en la afección recíproca. Tampoco puede ser reducido a un mero devenir óntico en cuanto discurrir y desaparecer $y$, de ningún modo, a un hacer que dependa de la voluntad autoaseguradora que se afirma en un eterno retorno de lo Mismo. Porque el discurrir fáctico y el hacer concreto deben ser ya entendidos -en coherencia con esta línea interpretativacomo formas de un operari óntico que son actualizaciones o realizaciones de una profundidad ontológica emergente.

El devenir en cuanto engendramiento y destrucción se nos revela ahora, no como el movimiento de un ser-producido y un caducar entitativos, sino 
como aparición y desaparición de actualizaciones diferentes que corporeizan una riqueza intensiva emergente. Partiendo del fondo diferencial de fuerzas -ápeiron intensivo-, tiene por finalidad este devenir su propia determinación. $\mathrm{Y}$, puesto que esta última ha de contener en formas concretas al ilimitado potencial del que emerge, no puede tender más que a la mayor riqueza posible de diferenciaciones determinadas. Puede ser entendido, de un modo más preciso, el ser de lo generado como su sostenerse qua diferencia en el seno de una multiplicidad. La de-generación destructiva, consecuentemente, coincide con la pérdida de tal carácter diferencial y, así, con su consunción en una autoidentidad de lo generado que equivale a la muerte. Corroboraremos tal carácter del devenir genético a propósito del modelo que introduce G. Simondon.

En el marco de una concepción del ser como potencia generadora, G. Simondon ha concretado el dinamismo de la physis que hemos descrito en los procesos de individuación. Todo ser concreto -individuo-es un mixto tensional, o relación diferencial tensa, entre su devenir individuado y el ámbito de lo preindividual que lo recorre inmanentemente. Este ámbito es, ante todo, un plano intensivo y "problemático", en la medida en que se configura como una retícula de fuerzas en tensión que puede ser entendida como una situación irresuelta, un problema real (Simondon 2009: 480). El individuo es la emergencia de una "resolución" en la que es contenida, bajo ciertos límites de metaestabilidad, la tensión inestable en que consiste la problematicidad pre-individual, ilimitada si la consideramos en sí misma. El ser, en toda su amplitud, consiste en lo contrario de lo que llama un "ser monofásico", cuyo modelo filosófico se remonta al hilemorfismo aristotélico: un ser idéntico a sí mismo cuyo devenir se limita al despliegue o realización de tal identidad esencial presupuesta. Este ser "está resuelto de antemano" (id.: 486) y no llega a generar nada diferente a sí mismo. Por el contrario, el ser, en cuanto "polifásico", es siempre el des-fase consigo mismo, tensión entre su ser intensivo preindividual y la inmensa variabilidad de formas individuadas en las que se conforma sin agotarse en ellas. Así, "tiene en sí mismo con qué ser más de lo que es en su actual estructura (...); es más rico que la coherencia consigo mismo" (id.). Este de-venir no afecta al ente como un discurrir meramente cronológico, sino que caracteriza al esenciarse (en un sentido intensivo) del ser mismo, es decir, a su auto-diferenciación, de tal modo que "no se puede decir que el ser deviene; el devenir es ontogénesis, púøıৎ” (id.: 48).

Como en el caso de Nietzsche, la multiplicidad que deviene no posee aquí un alfa y un omega, principio causal primero y telos apriórico (id. 474, 479). Conforma variaciones diferentes del ser. Ahora bien, este modelo permite precisar las nociones de generación y destrucción en el sentido ya sugerido. El ser de lo generado es su diferencia, podemos añadir ahora, no sólo con el resto de los seres, con los que está en relación. Es, además, diferencia en su propia 
conformación interna. "En ese sentido podemos definir al individuo como un ser limitado, pero a condición de entender por ello que un ser limitado es un ser polarizante" (id.: 130), lo que quiere decir que incorpora en sí al desfase del ser en el campo de una resolución definida. Cada individuo es más que sí mismo; es diferencia tensional entre su in-sistencia preindividual y la encarnación que representa, en la cual aquella no se agota. De ahí que tienda a desbordarse y a transfigurarse; "está sobre el límite mismo del ser" (id.: 184). Ello implica que cada individuación lleva en sí el riesgo de su aniquilación. Sostiene su sergenerado en la medida en que mantiene la diferencia o desproporción consigo mismo: hacerse idéntico a sí mismo equivale a la destrucción o de-generación, por la cual pierde la individuación y se integra en el dédalo de relaciones intensivas del ser. Especial realce alcanza este drama del ser en lo viviente, en el que la crisis demanda, para ser superada, una auténtica auto-transfiguración:

\begin{abstract}
"Sólo un individuo cuyas transformaciones fueran previsibles podría ser considerado como inmortal" (...). "Cuanta menos tensión, más aproximación a la desaparición o a la muerte (...) El individuo pierde poco a poco su plasticidad, su capacidad de volver metaestables las situaciones, y de hacer de ellas problemas con múltiples soluciones. Se podría decir que el individuo viviente se estructura cada vez más en sí mismo, y tiende de ese modo a repetir sus conductas anteriores, cuando se aleja del nacimiento" (id.: 352 ).
\end{abstract}

Tocada por la influencia tanto de Nietzsche como de Simondon, la comprensión del ser deleuzeana nos permitirá precisar con mayor profundidad el carácter tensional del dinamismo genético-intensivo. Encontramos un apoyo en la caracterización de la génesis como vínculo entre una dimensión ontológicogenerativa "virtual" y su "efectuación" (encarnación, materialización) en la dimensión óntica y representativa de lo "actual". "La génesis no va de un término actual, por más pequeño que sea, a otro término actual en el tiempo; sino de lo virtual a su actualización" (Deleuze 2002: 279). El ámbito simondoniano de lo preindividual encuentra su análogo en el deleuzeano espacio de lo virtual. Esta profundidad del ser -que es plenamente real- es, considerada en sí misma, indeterminada: es el mundo de lo intensivo, hundido en relaciones disyuntivas cuya textura problemática lo cualifica como instancia irresuelta que se resuelve en el plano, heterogéneo respecto a él, de lo actual (Deleuze 2002: 320). Es el sentido de la heterogeneidad entre lo virtual y lo actual lo que nos interesa destacar. Reside ésta en la acción recíproca y tensional que mantienen entre sí. El paso de lo virtual a su actualización o efectuación concreta es una diferenciación que lo transforma. "La naturaleza de lo virtual es tal que actualizase es diferenciarse para él” (id.: 301). Y lo actual, en sus múltiples relaciones, pone en vigor la diferenciación que incorpora generando, a su vez, diferencia en el mundo virtual. "Por lo tanto, el movimiento tiene dos caras, 
tan inseparables como el derecho y el revés, como el reverso y el anverso: es relación entre partes y es afección del todo", de forma parecida a como en el contexto del cine "unos personajes se mueven: ellos modifican sus posiciones respectivas en el conjunto (...), pero esta modificación sería enteramente arbitraria si no expresa también algo que está cambiando, una alteración cualitativa, incluso ínfima en el todo que pasa por este conjunto" (1984: 3637). Entre ambas caras de la génesis hay una lucha, podríamos concluir, por la cual están "anulándose, contradiciéndose" (1986a: 70).

Se desprende de lo anterior con mayor claridad -nos parece- que, consistiendo la generación (de lo actual individuado) en una diferenciación del ser (virtual), ha de poder mantener su propia diferencia interna o desproporción consigo mismo como condición de su relación afectante respecto a tal fondo diferencial. La identidad consigo mismo equivale a su desaparición. Y no en virtud de un mero dinamismo óntico, sino en cuanto pérdida de la diferenciación que corporeiza o actualiza.

Esta peculiaridad del ser como génesis lo hace inasimilable, a nuestro juicio, al acontecimiento de ser como sentido. Es cierto que Heidegger describe la diferencia entre ser y ente como contienda, tal y como señalamos más arriba y que, en consecuencia, comprende la articulación diferenciadora como un entre o pliegue. Pero dicho intersticio litigioso establece una intimidad entre los extremos del ser y el ente. Y ello porque la diferencia es el espacio, al mismo tiempo, de una mismidad. "El ser, en el sentido de la sobrevenida [Überkommnis] que desencubre, y lo ente como tal, en el sentido de la llegada [Ankunft $]$ que se encubre, se muestran como diferentes gracias a lo Mismo [das Selbe], gracias a (...) ese Entre [Zwischen] dentro del cual la sobrevenida y la llegada entran en relación, se separan y se reúnen" (1998:140-141). Como hemos intentado mostrar en otro lugar (Sáez Rueda 2018), Heidegger prima en la diferencia al carácter de intimidad habitable. Su mismidad intersticial es, en efecto, lo que permite la inmersión del ser humano en el ser como albergue o morada acogedora y la mutua correspondencia entre ser y pensar (en cuanto Ereignis). Es por ello por lo que caracteriza, en ciertas ocasiones, la relación resuelta o propia del Dasein con el ser en términos de una "in-sistencia (o instancia) abrigadora" -bergende Inständigkeit-(2003: 24).

$\mathrm{Si}$ Heidegger reprocha a Nietzsche que, en su pensamiento el devenir presupone la repetición de lo Mismo en cuanto voluntad de autoaseguramiento -como se señaló y hemos puesto en cuestión-, podemos poner reparos ahora a su propia interpretación del devenir como esenciación. La mismidad del ser señalada anteriormente es supuesta, en efecto, en la multiplicidad del ente. "El ser sólo esencia como único, mientras que por el contrario el ente es, según el caso, éste o aquel, tal cosa y no la otra. (...) [El ser] constantemente es, en tanto que lo único, lo Mismo -das Selbe- 
(1989: 110-111). Y aunque éste no debe ser confundido con lo Igual (das Gleiche), conserva un resto identitario que la concepción genético-intensiva que venimos describiendo está en disposición de rebasar, como señala, a nuestro juicio acertadamente, Deleuze. En la medida en que el ser genético virtual es ya diferencia, su propia diferenciación en lo actual no supone una mismidad. Lo que se repite en el devenir, pues, no es lo Mismo, sino la diferencia en cuanto tal (Deleuze 2002: 77-80).

Aunque el idealismo alemán partió de una concepción del ser como identidad absoluta, ofrece, en un escenario distinto, una aprehensión del ser como physis que rehúye la suposición de una intimidad albergante. El ser incorpora, en tal escenario, un ingrediente desgarrado y hasta trágico que desacredita, a nuestro juicio, el intento heideggeriano de asimilarlos filosóficamente.

\subsection{La diferencia genética entre lo orgánico y lo aórgico en el idealismo y el intento heideggeriano de asimilación fenomenológico-aleteiológica}

El idealismo alemán se nos ofrece como un escenario especialmente apropiado para poner de manifiesto el olvido heideggeriano del ser como génesis intensiva. Constituye el momento moderno quizás más vigoroso en el que es recobrada la comprensión del ser como physis desde una ontología genética. Y esta circunstancia opera, quizás, en el gran interés que Heidegger ha mostrado en este movimiento, cuyos potenciales vierte en favor de su comprensión del ser como acontecimiento de sentido.

Deleuze hacía nacer su empirismo trascendental, proyecto clave en su filosofía, en la necesidad de rebasar la filosofía kantiana, como una "filosofía del condicionamiento", hacia una filosofía de la génesis que fuese capaz de remitir lo dado, no a la "experiencia posible" sino a la "experiencia real" que la genera (2002: 118). El punto de partida posee un sentido crucial y es coincidente con el del idealismo. La unidad de sujeto y objeto y, con ella, la de sensibilidad y razón y la del yo y la naturaleza, pendía en Kant de la apercepción trascendental, unidad de donación de experiencia y aprehensión del cogito. Y el problema residía en que la identidad del yo ahí supuesta podía sólo ser postulada pero no afirmada como una existencia real. El inicio fichteano toma asiento en este problema. La hetero-referencia sujetoobjeto presupone una auto-referencia, un Yo incondicionado como principio generador. Pero ello implica que no es un hecho (Tatsache), sino actividad originaria (Tathandlung). Esta potencia activa es principio de génesis respecto a toda conciencia (Fichte 2005: 41). La génesis adopta, además, esencialmente una disposición tensional, especificando así lo que hemos señalado ya como concerniente a una filosofía de la génesis en general: la tensión céntricoexcéntrica entre el movimiento "centrífugo" del yo finito, que hace surgir lo 
efectivo en su relación con el No-Yo, y el "centrípeto", que remite el anterior a las operaciones subyacentes del Yo absoluto (id.: 191-193).

En Schiller es desgarrada la identidad del yo fichteano y lanzada a un ideal inalcanzable. La génesis tiene lugar ahora en la tensión entre la "persona", como fondo indeterminado de lo humano en su potencialidad, y el "estado" o conformación efectiva. En su "anhelo de divinidad" el ser humano expresa la tendencia a una síntesis imposible: "la absoluta manifestación de la potencia -la realidad efectiva de todo lo posible- y la absoluta unidad de la aparición -la necesidad de todo lo real efectivo" (1990: XI, 137). Es claro que el fondo de potencia no es caracterizado, en sí mismo, como diferencial, como relación de fuerzas. Ahora bien, salvando las distancias, en Schiller es ya posible descubrir una tensión genética que mantiene una analogía con la tensión deleuzeana de lo virtual y lo actual. La tensión entre persona y estado constituye una disposición a la divinidad, unidad plena del ser humano, de manera que el fondo de potencia de la persona opera - dice Schiller- como una "virtualidad" (in der Anlage) que tiende a realizarse de hecho (id.: 132). Este ser desgarrado, así, "para no ser mera forma, tiene que dar realidad efectiva a lo virtual (Anlage)" (id.:, 137). Tal tensión implica que el devenir no está concebido al modo óntico, como movimiento hacia una meta y acabamiento, sino como emergencia hacia la riqueza y la variedad de manifestaciones. "Siendo el mundo algo extenso en el tiempo y variable, consistirá la perfección (...) en la máxima variabilidad y extensión posibles. Siendo la persona lo permanente en la variación, consistirá la perfección (...) en la máxima independencia e intensidad posibles" (id.: 144).

En sus comentarios a las cartas de Schiller, Heidegger interpreta al ser humano caracterizado por Schelling en términos de la analítica existenciaria de Sein und Zeit, es decir, como auto-trascendimiento y proyecto, permitiendo una recreación del ser (2005b: 115; v. Acosta López 2009). Basta esta breve referencia para percatarnos de que Heidegger insiste en absorber la dimensión de génesis en la fenomenológica. Obvia el drama humano que se juega en el devenir entre generación y destrucción. La tensión, en efecto, entre persona y estado es también la equivalente a la que existe entre lo aórgico, es decir, la physis como lo indefinido des-organizado o caótico, y lo orgánico como conformación auto-organizada. Esta lucha, inherente a la génesis del ser, a la que referirá Hölderlin, es ya descubierta por Schelling (v. Llorente Cardo 2012). En su acción debe el hombre hundirse en lo aórgico de la persona y conjurarlo para renacer en lo orgánico del estado:

\footnotetext{
"Hay que volver, en cierto modo, a aquel estado negativo de indeterminación (...) Pero este estado se hallaba desierto de todo contenido, y ahora se trata, en cambio, de producir la misma indeterminación, la misma ilimitada determinabilidad pero junta con el mayor posible contenido" (id.: 173).
} 
El problema de la génesis retoma una fundamental dirección en Schelling que pone en vigor con especial claridad al ser como physis, con lo cual nos acercamos de lleno a nuestra problemática central. Reprocha a Fichte que la dimensión genética del ser esté vinculada a una subjetividad fontanal. En su Sistema del idealismo trascendental pone en cuestión la exclusividad del Yo como fuente incondicional anterior a la separación entre sujeto y objeto. La naturaleza no puede ser reducida a una negatividad, No-Yo finito, pues hace frente al Yo soy en toda su radicalidad y debe ser pensada también como alteridad incondicionada. De ahí surge la necesidad de un pensar como sistema, capaz de mostrar la concurrencia de una doble vía: la que alcanza a la naturaleza desde la misma exposición del yo incondicionado y la inversa. Esto significa entender la naturaleza como natura naturans. "La teoría acabada de la naturaleza sería aquella en virtud de la cual toda la naturaleza se resolviera en un inteligencia" (Schelling 1988: 151). En Sobre la esencia de la libertad humana tiene lugar un avance esencial en esta dirección. La physis no puede ser una cosa (como, según Schelling termina siendo en Spinoza). Es autoactividad, espíritu, absoluta libertad. La génesis, desde este punto de vista, implicaría una diferencia entre lo generado, ser en cuanto existencia, y la potencia generadora, el fundamento de la existencia, que es "la naturaleza en Dios" (2000: 163), tiniebla o noche oscura (id:: 169). Ahora bien, ambos presuponen un fundamento infundado como actividad creadora, un Un-grund indeterminado, anterior a todas las distinciones, incluida la que separa a la noche de la luz. Y en este punto reencontramos lo más importante en lo que concierne a nuestras reflexiones. La génesis es una auto-revelación en la que entran en juego lo ápeiron y la limitación y, a nuestro juicio, lo aórgico y lo orgánico. "Tras el hecho eterno de la autorrevelación todo es en el mundo (...) regla, orden y forma, pero con todo, lo carente de regla subyace siempre en el fundamento, como si pudiera volver a brotar de nuevo" (id.: 167), de modo que, a la base de la realidad de las cosas actúa un "resto que nunca se puede reducir, aquello que ni con el mayor esfuerzo se deja disolver en el entendimiento" (id.: 360).

La interpretación de Heidegger que toma en consideración este recorrido de Schelling pone de manifiesto una vez más la asimilación de la génesis al devenir de sentido. Schelling se habría aproximado como pocos a la presentación explícita de la diferencia óntico-ontológica. Al encontrar, bajo la relación sujeto-objeto, el fundamento como sistema de lo incondicionado, Schelling estaría refiriéndose -en su envés impensado- al único sostén de tal correspondencia, a la verdad como alétheia, por cuyo acontecer tiene lugar la "patencia del ente mismo" (Heidegger 1985: 63; cfr. 62-64). En la medida en que el fundamento del sistema es la libertad, habría sido indicada, además, la originaria indisponibilidad del ser, en la que arraiga la "fundación del 'Ser'ahí", resultado con el cual Heidegger mismo reconoce ir "más allá de Schelling y de la manera como se ha tratado esa tarea en el pasado" (id.: 64). 
Reencontramos ahora la asimilación del ser genético-intensivo de la physis con el que iniciamos nuestra reflexión. Al pensar de Schelling le es inherente anunciar esa misma justicia (diké) -piensa Heidegger- a la que se refería la sentencia de Anaximandro, es decir, la del acuerdo entre descubrimiento y encubrimiento. Con el "sistema" es pensado el todo del ente como un ensamble, el cual supone el dinamismo del ensamblar, es decir, el ser. "Donde hay ser hay ensamble (Gefüge) y ensamblamiento - Fügung-" (id.: 60; GA 42: 86), algo que el presocrático advertía:

"Ya la sentencia más antigua de la filosofía occidental que ha sido trasmitida a

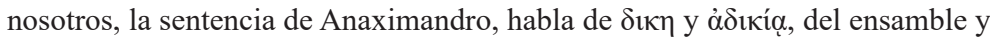
el des-ensamble (Unfug) del Ser" (id.).

El juego entre justicia e injusticia que es inherente al ser como génesis, es decir, el de la generación y la destrucción, es, sin embargo, expresado por Schelling con belleza:

\footnotetext{
"Todo nacimiento es un nacimiento desde la oscuridad a la luz; la semilla ha de ser hundida en la tierra y morir en las tinieblas a fin de que pueda alzarse una forma luminosa más hermosa y desarrollarse bajo los rayos del sol. El hombre se forma en el seno materno, y sólo desde la oscuridad de lo que carece de entendimiento (....) nacen los pensamientos luminosos" (2000: 169).
}

Esta tensión entre generación y destrucción creativa es más clara, si cabe, en Hölderlin, en cuya obra Heidegger siguió viendo una llamada al ser como acontecimiento de sentido, aunque en el seno de la palabra poética. "El pensador dice el ser. El poeta nombra lo sagrado" (Heidegger 2000c: 257258). Tal nombrar constituye una "fundación" (Stiftung) del ser" (1993: 61): lo extrae del olvido y procura que su acontecimiento abra un mundo de sentido en cuanto hospedaje habitable. Tratándose de un poeta, es posible que esto sea cierto. Ahora bien, ¿invoca Hölderlin sólo a este ser como urdimbre de sentido? El poeta insiste en que la "totalidad de lo viviente" está atravesada por un litigio entre lo aórgico y lo orgánico en el que opera con intensidad trágica el de la generación y la aniquilación. En ella se expresa tanto la intimidad del hombre respecto a "todo lo que vive", como la "separación efectivamente real" (Hölderlin 1976: 81). Y es que esta "más alta reconciliación" supone que el sujeto, "por cuanto expresa la intimidad más profunda, niega por completo su persona" (id.: 105), con lo cual lo orgánico y lo aórgico se vinculan justo en el punto de la "más alta hostilidad" (id.: 107). Esta tensión diferencial no sólo es de carácter intensivo, algo que Heidegger pasa por alto; arrastra, además, un carácter trágico que no es aprehendido en el juego de la desocultación y el encubrimiento. La diferencia por la que hay generación no constituye una 
intimidad albergante, como ocurre en el caso de la diferencia fenomenológicoaleteiológica. Tal intimidad, por el contrario, debe ser comprendida como de-generación o destrucción. Y es que "esta desmesura real de la intimidad procede de la hostilidad y de la más alta discordia” (id.: 109).

\section{Reflexiones finales y reapertura}

El sentido de nuestras conclusiones puede exponerse a partir del último escenario en el que hemos examinado el olvido heideggeriano del ser como génesis intensiva. Si Schelling es para Heidegger, según manifestación expresa, la "cumbre metafísica del idealismo alemán" (GA 49: 1) y si, además, ofrece "con plena determinación el núcleo fundamental de la metafísica de Occidente" (id.: 2), podría decirse que en su pensamiento se cifra algo esencial del olvido del ser. Esto esencial consiste para Heidegger en haber realizado una unidad entre libertad y voluntad en el fundamento, es decir, en haber concebido el ser, finalmente, en términos de voluntad de voluntad, con lo cual se vincula al error de Nietzsche. Ambos, por tanto, culminan la metafísica de la subjetividad comenzada por Descartes ( $c f$. 1985: 214-225). "Ese doble gran naufragio de grandes pensadores (...) es el destellar de un nuevo comienzo" (id.: 4), del comienzo propiamente heideggeriano.

La confrontación con la metafísica de la voluntad no es tangencial en el pensamiento heideggeriano. Todo el olvido del ser está fundado en la conversión del ser en mero ente, un acontecimiento que pone en movimiento, ya desde el principio de la filosofía griega en Platón y Aristóteles, la voluntad de dominio sobre todo lo existente. El final de la filosofía como metafísica, la comprensión técnica del mundo, es la consumación de tal inicio, en el que se explicita el dominio como voluntad de voluntad (1968: 132-133). El especial interés de Heidegger en la confrontación con Nietzsche y con el idealismo alemán, cuya expresión álgida se encuentra en Schelling, nace de esta necesidad imperiosa de oponer la comprensión del ser en cuanto acontecimiento fenomenológicoaleteiológico como alternativa. Ahora bien, hemos intentado mostrar, con la ayuda de G. Deleuze, que la voluntad de poder nietzscheana debe ser entendida como el diferenciante de las relaciones intensivas y, así, como potencia genética.

Dejando a un lado la aplicación de este problema a propósito de las figuras de Nietzsche y Schelling, hemos ido congregando los rasgos de una ontología del ser como génesis intensiva, persiguiendo la interpretación heideggeriana de la physis. Heidegger no ha sido capaz de distinguir entre una ontología de la mera voluntad y esta ontología genético-intensiva que, presente en el mundo presocrático, hoy vemos prosperar en una rica línea de pensamiento que incluye a Simondon y a Deleuze. Por el contrario, disuelve, en diferentes 
escenarios filosóficos, el devenir del ser como génesis intensiva en el devenir del ser en su sentido fenomenológico-aleteiológico y vincula la consideración de una génesis no asimilable de este modo a la afirmación de un devenir meramente óntico. Hemos intentado mostrar que es posible pensar el devenir de la génesis como una diferencia óntico-ontológica específica e irreductible a la del ser como descubrimiento-ocultamiento de sentido. Si nuestros argumentos merecen credibilidad, cabe deducir que la denuncia del olvido del ser (como sentido) tiene como contrapartida el olvido heideggeriano del ser como génesis intensiva.

Al hilo de nuestra argumentación hemos trenzado otras tesis más concretas, aunque secundarias. En particular, la de que la diferencia genética entre lo ontológico y lo óntico es tensional y la de que la generación de lo individual implica, asimismo, una tensión cuya disolución en una auto-identidad conduce a la de-generación destructiva. Y, junto a ello, que la diferencia fenomenológico-aleteiológica es tributaria de una intimidad albergante no asumible en la genético-intensiva, cuya tensionalidad conduce, en el extremo, a una configuración trágica.

Tal vez sea necesaria hoy una vinculación sin confusión de estas dos ontologías y, así, de la existencia en el sentido y de la pertenencia a la génesis natural. Hemos intentado aunarlas en otro lugar y a propósito de otros problemas precisos (Sáez Rueda 2009: 74-121 y 162-179; 2015: 75-132), pero la problemática que aquí es abierta exigiría una investigación de más largo aliento.

En el tiempo de la "huida de los dioses", y cuando, a pesar de ello, "sólo un dios puede salvarnos", Hölderlin cantaba, nos dice Heidegger, al dios venidero, es decir, a la reanimación del acontecimiento del ser como algo digno de ser venerado. En la época, también, en la que, como el propio Heidegger nos señalaba, el ser humano está a punto de abalanzarse sobre la totalidad de la tierra y su atmósfera, tal vez podamos reclamar, en virtud de una ontología de la génesis, la invocación de Hölderlin a la unión con el todo de la naturaleza, a pesar del destino trágico que ello pueda comportar.

\section{Bibliografía}

Acosta López, M. d. R. (2009): “The secret that is the work of art: Heidegger's Lectures on Schiller", Phenomenology, 39, 135-163.

Ávila Vázquez, M. O. (2011): "En torno a la sentencia de Anaximandro. Dos interpretaciones o sobre la injusticia y la reparación”, Universitas Philosophica, 56 (28), 61-83. 
Calvo Martínez, T. (2000): “La noción de physis en los orígenes de la filosofía griega", Daímon, 21, 21-38.

Deleuze, G. (2015): La subjetivación. Curso sobre Foucault, Buenos Aires, Cactus.

Deleuze, G. (2002): Diferencia y repetición, Buenos Aires, Amorrortu.

Deleuze, G. (1989): Lógica del sentido, Barcelona, Paidós.

Deleuze, G. (1986a): Nietzsche y la filosofía, Barcelona, Anagrama.

Deleuze, G. (1986b): La imagen-tiempo: Estudios sobre cine 2, Barcelona, Paidós.

Deleuze, G. (1984): La imagen-movimiento: Estudios sobre cine 1, Barcelona, Paidós.

Fichte, J. G. (2005): Fundamento de toda la doctrina de la ciencia, Pamplona. [orig.: 1794]

Foucault, F. (1991): “Nietzsche, la genealogía, la historia”, en Microfísica del poder, Madrid, La Piqueta.

Heidegger, M. (2005a): Parménides, Madrid, Akal. [GA 54, orig.: 1942-43]

Heidegger, M. (2005b): Übungen für Anfänger. Schillers Briefe über die ästhetische Erziehung des Menschens. Wintersemester 1936/37, Deutsche Schillergesellschaft, Marbach am Neckar.

Heidegger, M. (2003): Aportaciones a la filosofía. Acerca del evento, Buenos Aires, Almagesto. [GA 65; orig.: 1936-38]

Heidegger, M. (2001a): “Ciencia y meditación”, en Conferencias y artículos, Barcelona, Serbal, 33-51. [GA 7; orig.: 1936-1952]

Heidegger, M. (2001b). Introducción a la metafísica, Buenos Aires, Nova. [GA 40; orig.: 1935]

Heidegger, M. (2000a): Nietzsche, Barcelona, Destino. [GA 6; orig.: 19361946]

Heidegger, M. (2000b): "Sobre la esencia y el concepto de la physis. Aristóteles, Física B, 1", en Hitos, Madrid, Alianza [GA 9; orig.: 1939]

Heidegger, M. (2000c): "Carta sobre el 'humanismo"”, en Hitos, Madrid, Alianza, 259-298. [GA 9; orig.: 1946]

Heidegger, M. (1998): "La constitución onto-teo-lógica de la metafísica”, en Identidad y diferencia, Barcelona, Anthropos, 99-158. [GA 11; orig.: 1957]

Heidegger, M. (1995): "La sentencia de Anaximandro", en Caminos del bosque, Madrid, Alianza, 239-277. [GA 5; orig.: 1946]

Heidegger, M. (1993): Interpretaciones sobre la poesía de Hölderlin, Barcelona, Ariel. [GA 4; orig.: 1936-68]

Heidegger, M. (1989): Conceptos fundamentales, Madrid, Alianza. [GA 51; orig.: 1941]

Heidegger, M. (1985): Schelling y la libertad humana, Caracas, Monte Ávila. [GA 42 y 49; orig.: 1936] 
Heidegger, M. (1968): "El final de la filosofía y la tarea del pensar", en VVAA, Kierkegaard vivo, Madrid, Alianza, 130-153. [GA 14 1; orig.: 1964]

Heidegger (1951): El ser y el tiempo, México, F.C.E. [GA 2; orig.: 1927]

Hölderlin, F. (1976): Ensayos, Madrid, Hiperión. [SWgSA, 4]

Llorente Cardo, J. (2012): "Entre lo orgánico y lo aórgico: figuras de la reconciliación en las teorías estéticas de Schiller y Hölderlin”, Contrastes, XVII, 179-195.

Nietzsche, F. (2003): Los filósofos preplatónicos, Madrid, Trotta.

Nietzsche, F. (2002): El nacimiento de la tragedia, Madrid, Alianza.

Nietzsche, F. (1986): Fragmentos póstumos (IV). 1885-1889, Madrid, Tecnos.

Rojas Jiménez, A. (2012): "La influencia de Schelling en la lección de Heidegger de 1942/43", Thémata. Revista de Filosofía, 45, 383-394.

Sáez Rueda, L. (2018): "Diferencia óntico-ontológica y mismidad. Una interpretación de la herencia heideggeriana en M. Foucault y G. Deleuze", Pensamiento. Revista de investigación e información filosófica, vol. 74, $\mathrm{n}^{\mathrm{o}}$ 281, 717-738.

Sáez Rueda, L. (2015): El ocaso de Occidente, Barcelona, Herder.

Sáez Rueda, L. (2009): Ser errático. Una ontología crítica de la sociedad, Madrid, Trotta.

Schelling, F.W.J. (2000): Investigaciones filosóficas sobre la esencia de la libertad humana y los objetos con ella relacionados, Barcelona, Anthropos. Ed. bilingüe. [SW. VII; orig.: 1807]

Schelling, F.W.J. (1988): Sistema del idealismo trascendental, Barcelona, Anthropos. [SW. III; orig.: 1800]

Schiller, J. C. (1990): “Cartas sobre la educación estética del hombre”, en Escritos sobre Estética, Madrid, Tecnos.

Segura Peraita, C. (2018): "Heidegger, 1931-1939: interpretaciones sobre la kínesis. Hacia una ontología dinámica y aleteiológica”, Discusiones Filosóficas, 19 (32), 135-150.

Simondon, G. (2009): La individuación a la luz de las nociones de forma y de información, Buenos Aires, Cactus/La Cebra. 